\title{
Enflurane Induces Contracture of in Vitro Muscle from a Patient with Malignant Hyperthermia
}

\author{
Naofumi Iwatsuki, Yoshinisa Koga and Keisuke Amaha \\ Department of Anesthesiology, Tohoku University School of \\ Medicine, Sendai 980
}

\begin{abstract}
Iwatsuki, N., Koga, Y. and Амaнa, K. Enflurane Induces Contracture of in Vitro Muscle from a Patient with Malignant Hyperthermia. Tohoku J. exp. Med., 1983, 140 (2), 221-222 — The possibility of enflurane being an inducer of malignant hyperthermia ( $\mathrm{MH}$ ) was examined by using the contracture test in in vitro muscle from a patient with $\mathrm{MH}$. An administration of $2 \%$ enflurane elicited contracture in MH muscle and an elimination of enflurane relaxed this contracture. This result, therefore, strongly suggested that enflurane is the one of the trigger-agents for MH.
\end{abstract}

Potent inhalation anesthetics may be capable of inducing malignant hyperthermia (MH). It has been widely accepted that halothane induces MH. However, whether enflurane would induce MH has not been confirmed. Caropreso et al. (1975) and Pan et al. (1975) reported cases suggesting the possibility of enflurane as a trigger-agent of $\mathrm{MH}$.

At present an induction of muscle contracture in vitro muscle is the most reliable test of screening whether some drug induces MH or not (Gronert 1980). Although the enhancement of caffeine-mediated muscle contracture by the administration of enflurane in vitro was demonstrated in frog skeletal muscle (Reed and Strobel 1978) and in human skeletal muscle susceptible to MH (Britt et al. 1980) direct evidence of contracture response to a single administration of enflurane has not been reported. We encountered a patient with MH, thus examined the contracture response of in vitro muscle from this patient to enflurane.

\section{Methods and Materials}

A 14-year-old boy had a severe hyperthermic episode with muscle rigidity under halothane anesthesia. Five months later of this episode muscle biopsy was performed from tensor fasciae latae for the differential diagnosis of MH. The obtained muscle specimen was dissected to several strips $(20 \mathrm{~mm}$ in length and $5 \mathrm{~mm}$ in width). Three of these strips were used for this study. Along this study, the caffeine-contracture test using other muscle strips from the same specimen confirmed the susceptibility of this patient to MH. The muscle strips were suspended in an organ bath which contained $40 \mathrm{ml}$ of Krebs-Henseleit's solution oxygenated with $95 \% \mathrm{O}_{2}-5 \% \mathrm{CO}_{2}$ gas mixture and kept at $36^{\circ} \mathrm{C}$ by surrounding thermo-bath. The experimental setup was similar to that used for an isolated heart muscle study (Iwatsuki et al. 1980), except electrical stimulation which in this study was of supramaximal intensity and $20-\mathrm{msec}$ duration at a frequency of $0.1 \mathrm{~Hz}$. Isometric twitch tensions and resting tensions were measured continuously under the preload of $0.5 \mathrm{~g}$. Enflurane vapor obtained by passing $\mathrm{O}_{2}-\mathrm{CO}_{2}$ gas mixture through an "Enflurotec" vaporizer was bubbled in the organ bath.

Received for publication, December 1, 1982. 


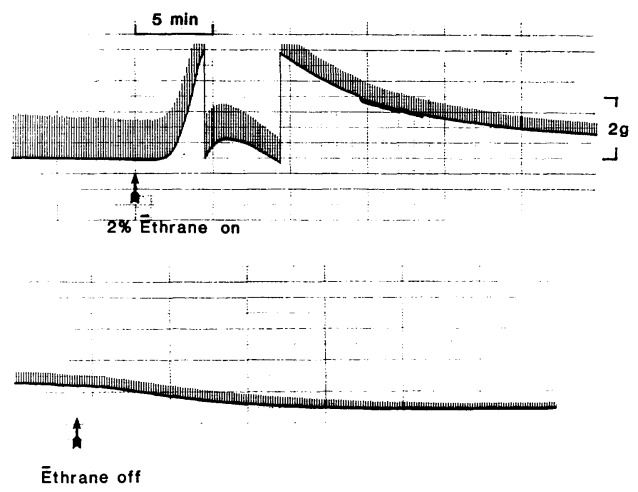

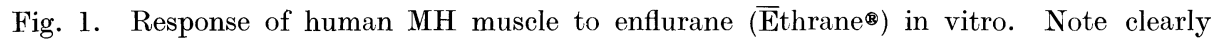
increased basal tension (contracture) by the administration of Ethrane. Position of the trace was moved downwards at the maximal contracture response.

\section{Results and Discussion}

All three muscle strips used for this study showed the contracture response (increase in resting tension) by the administration of $2 \%$ enflurane. By the elimination of enflurane these contractures were relaxed to the pre-administration level. Fig. 1 illustrates the typical response of $\mathrm{MH}$ muscle to enflurane.

This is the first report illustrated a direct contracture response of in vitro $\mathrm{MH}$ human muscle to enflurane. It has been widely accepted that a drug elicited contracture on in vitro MH muscle or enhanced the caffeine-mediated contracture may induce MH (Gronert 1980). In normal muscle an administration of enflurane did not produce any muscle contracture in our preliminary study. This result, therefore, strongly suggested that enflurane is the one of the trigger-agents for MH.

\section{References}

1) Britt, B.A., Endrenyi, L., Frodis, W., Scott, E. \& Kalow, W. (1980) Comparison of effects of several inhalation anaesthetics on caffeine-induced contractures of normal and malignant hyperthermic skeletal muscle. Canad. Anaesth. Soc. J., 27, 12-15.

2) Caropreso, P.B., Gittleman, M.A., Reilly, D.J. \& Patterson, L.T. (1975) Malignant hyperthermia associated with enflurane anesthesia. Arch. Surg., 110, 1491-1493.

3) Gronert, G.A. (1980) Malignant hyperthermia. Anesthesiology, 53, 395-423.

4) Iwatsuki, N., Matsukawa, S. \& Iwatsuki, K. (1980) A weak negative inotropic effect of protamine sulfate upon the isolated canine heart muscle. Anesth. Analg., 59, 100102.

5) Pan, T., Wollack, A.R. \& DeMarco, J.A. (1975) Malignant hyperthermia associated with enflurane anesthesia: A case report. Anesth. Analg., 54, 47-49.

6) Reed, S.B. \& Strobel, G.E., Jr. (1978) An in-vitro model of malignant hyperthermia: Differential effects of inhalation anesthetics on caffeine-induced muscle contractures. Anesthesiology, 48, 254-259. 